\title{
The impact of computerized physician order entry on prescription orders: A quasi-experimental study in Iran
}

\author{
Mohammad Khammarnia ${ }^{1}$, Roxana Sharifian ${ }^{2 *}$, Farid Zand ${ }^{3}$, Omid Barati $^{4}$, Ali Keshtkaran ${ }^{4}$, \\ Golnar Sabetian ${ }^{5}$, Nasim Shahrokh ${ }^{6}$, Fatemeh Setoodezadeh ${ }^{1}$
}

\begin{abstract}
Background: One way to reduce medical errors associated with physician orders is computerized physician order entry (CPOE) software. This study was conducted to compare prescription orders between 2 groups before and after CPOE implementation in a hospital.

Methods: We conducted a before-after prospective study in 2 intensive care unit (ICU) wards (as intervention and control wards) in the largest tertiary public hospital in South of Iran during 2014 and 2016. All prescription orders were validated by a clinical pharmacist and an ICU physician. The rates of ordering the errors in medical orders were compared before (manual ordering) and after implementation of the CPOE. A standard checklist was used for data collection. For the data analysis, SPSS Version 21, descriptive statistics, and analytical tests such as McNemar, chi-square, and logistic regression were used.

Results: The CPOE significantly decreased 2 types of errors, illegible orders and lack of writing the drug form, in the intervention ward compared to the control ward $(\mathrm{p}<0.05)$; however, the 2 errors increased due to the defect in the CPOE ( $<<0.001)$. The use of CPOE decreased the prescription errors from $19 \%$ to $3 \%(p=0.001)$, However, no differences were observed in the control ward $(\mathrm{p}<0.05)$. In addition, more errors occurred in the morning shift $(\mathrm{p}<0.001)$.

Conclusion: In general, the use of CPOE significantly reduced the prescription errors. Nonetheless, more caution should be exercised in the use of this system, and its deficiencies should be resolved. Furthermore, it is recommended that CPOE be used to improve the quality of delivered services in hospitals.
\end{abstract}

Keywords: Computerized physician order entry, Prescription error, Public hospital

Copyright $@$ Iran University of Medical Sciences

Cite this article as: Khammarnia M, Sharifian R, Zand F, Barati O, Keshtkaran A, Sabetian G, Shahrokh N, Setoodezadeh F. The impact of computerized physician order entry on prescription orders: A quasi-experimental study in Iran. Med J Islam Repub Iran. 2017 (3 Oct);31:69. https://doi.org/10.14196/mjiri.31.69

\section{Introduction}

Medical errors are an inevitable reality in the health system. These errors, especially medication errors (MEs), can lead to morbidity and mortality in patients (1). MEs in hospitals are common, expensive, and sometimes harmful to patients (2). Many of MEs and mistakes occur during the ordering process and may lead to illegible prescriptions for nurses and other medical staff who prepare the services for patients, while most errors are preventable (3, 4). Prescription errors occur in up to $40 \%$ of medication orders written for hospital inpatients (5). MEs lead to

Corresponding author: Dr Roxana Sharifian, sharifianr@sums.ac.ir

1. Health Promotion Research Center, Zahedan University of Medical Sciences, Zahedan, Iran.

2. Department of Health Information Management, School of Management and Medical Information Sciences, Health Human Resources Research Center, Shiraz University of Medical Sciences, Shiraz, Iran.

3. Shiraz Anesthesiology and Critical Care Research Center, Department of Anesthesia and Critical Care Medicine, Shiraz University of Medical Sciences, Shiraz, Iran.

4. Department of Health Care Management, School of Management and Medical Information, Shiraz University of Medical Sciences, Shiraz, Iran.

5. Trauma Research Center, Shiraz University of Medical Sciences, Shiraz, Iran.

6. Student Research Committee, Shiraz University of Medical Sciences, Shiraz, Iran. longer hospital stay, increased medical costs, permanent disability, and even death (6).

Moreover, MEs in the intensive care unit (ICU) are frequent and result in attributable patient morbidity and mortality, increased length of ICU stay, and substantial extra costs (7). Computerized provider order entry (CPOE) is a new technology in health information technology, which runs to improve patient care, patient safety, decrease MEs and costs, and advance the health of the population $(4,8$, 9). CPOE system allows physicians to prescribe medica-

$\uparrow$ What is "already known" in this topic:

Computerized provider order entry (CPOE) is a new technology that improves patient care, patient safety, and decreases medical error. Although there is a need for CPOE in Iran, the use of this system has not been widespread in our country.

\section{$\rightarrow$ What this article adds:}

This study demonstrated the CPOE design and implementation in a tertiary hospital in Iran for the first time, which resulted in a decrease in prescription errors. 
tions electronically (10), eliminate the need for handwritten paper orders, and achieve cost savings through increased efficiency in hospitals (4). This system appears as an effective tool in reducing MEs (3). Moreover, the other benefits of CPOE are process standardization and improvement in documentation quality (11). Manias E et al. indicated that CPOE could reduce medical errors in ICUs more than other interventions (12). Moreover, Krive J et al. found that patient treatment orders prepared through electronic sets by CPOE were effective in reducing readmissions, lengths of stay, and mortality(13).

In addition, CPOE system with embedded clinical decision support system (CDSS) can significantly reduce certain types of prescription errors (14). Overall, to improve health care quality, implementation of CPOE with CDSS could yield substantial long-term savings to the society (15).

Some studies have shown the impact of CPOE in developed countries; Armada et al. found that CPOE has an impressive effect on the reduction of prescription errors in ICU wards (44.8\% to 0.8) (16). In addition, Hernandez et al. showed that the impact of this system on the prescription errors reduction is almost $92 \%$ (2). Nonetheless, the effect of CPOE in developing countries is not clear and most of them do not use the system due to financial problems (17).

There was not any specialized CPOE in Iranian hospitals, and Nemazi teaching hospital (affiliated to Shiraz University of Medical Sciences, SUMS) was the first and only hospital to use CPOE in Iran. The present study was conducted to compare prescription orders between 2 groups before and after CPOE implementation in Namazi teaching hospital in South of Iran. The other objective was to determine the frequency of medical errors in the wards and the impact of CPOE on each prescription error in the hospital.

\section{Methods \\ Design}

We conducted a before-after study in a tertiary academic medical center in Shiraz, Iran, from 2014 to 2016. Shiraz is a medical tourism center in South of Iran, and Nemazi teaching hospital is the largest (with more than 1200 beds) medical center in the city (1). Two ICU wards were selected for the study; the first (general ICU) with 10 beds, and the second (central ICU) with 4 beds; the 2 wards were next to each other. The wards were similar in the type of patients and prescription orders and provided the same services by the same physicians; however, they were different in the number of beds. In this study, the general ICU and central ICU were selected as intervention and control wards, respectively. In the intervention ward, the CPOE software was installed on a laptop, personal computer, and 2 tablets used by physicians and nurses. In this study, the patients' medical records were observed in the 2 ICUs before and after the intervention. The medical records, which had at least 1 order, were examined and made available to the researchers. The medical records that were not available were excluded from the study.

The CPOE software was designed in SUMS by an ex- pert team and identified as the first and only specialized CPOE system in Iran. Over a 6-month period, a pharmacist and an ICU physician, who were trained about the CPOE ordering process and were familiar with the ICU ordering process (both hand written and electronic), assessed the MEs at 2 times: first, 3 months before the implementation of the CPOE (manual ordering) (from July to Oct 2014), and second, after CPOE implementation (from December 15, 2015 to February 15, 2016). In the first step of data gathering, the medical records were assessed before CPOE intervention in the 2 wards. Then, CPOE was implemented in the intervention ward for 3 months (from September $1^{\text {st }}$ to December $1^{\text {st }}, 2016$ ), and the physicians entered their medical orders in the system rather than the manual method. Three months after the intervention, the medical records were assessed by a pharmacologist and an ICU physician in the both intervention and control wards.

\section{Study outcomes}

The main outcomes measured were the number and type of the prescribed errors when using manual prescriptions versus electronic prescription method. Data collection form was a standard checklist (1), designed based on the Clinical Governance Department of SUMS and consisted of 20 variables as follow: illegible order; error order (writing error order for a patient; e.g., ordering a wrong drug for a patient); wrong drug; not writing the drug form (The physician did not write the form of drug.); not writing drug dosage; wrong drug form; not writing the route; not writing the time to use the drug; wrong dosage; wrong drug time; wrong route; wrong medical test; wrong test time; wrong diet; and other errors such as drug interaction, interaction between drugs, which is potentially dangerous, and consultation error. The validity of the checklist has been examined in a previous study (16).

\section{Statistical Analysis}

Using SPSS software program (Version 21),we conducted the data analysis through descriptive statistics, chisquare (for comparison of the quantitative data between the 2 wards), and McNemar's test to compare the proportion of error types between before and after intervention in the each ward. Moreover, logistic regression model was used to determine the odds ratio of errors in the control ward compared to the intervention ward using Enter method. Besides, significance level was set at 0.05 . With respect to ethical considerations, as the medical records were examined in the study, there was no need to obtain patients' consent form; nonetheless, we considered the anonymity of the records. This study was approved by the ethics committee of SUMS (Code no: 6974).

\section{Results}

Before the intervention, about 1310 orders were recorded in the general ICU, of which 251 had at least 1 error (error rate; 19.1\%) and 920 orders were recorded in the central ICU, of which 136 had at least 1 error (error rate; 14.7). Also, after the intervention, 3045 orders were recorded in the general ICU (as intervention ward), of which 
92 had at least 1 error (error rate; $0.3 \%$ ); and 1263 orders were recorded in the central ICU (as control ward), of which 189 had at least 1 error (error rate; 14.9). Table 1 demonstrates the frequency, type, and rate of the prescribed errors in the intervention ward before and after the intervention in Nemazi Hospital.

As presented in Table 1, illegible error, no drug form, and no drug route were decreased in the intervention ward $(p=0.001)$. Moreover, wrong drug time was decreased in the intervention ward and it was near the significance level $(p=0.051)$. On the other hand, wrong drug form and wrong dosage were increased in the intervention ward after the CPOE intervention.

Table 2 demonstrates the frequency, type, and rate of the prescribed errors in the control ward before and after the intervention in Nemazi Hospital.

As presented in Table 2, although there were errors in the control ward before and after the intervention, illegible order, no drug form, wrong drug time, and wrong route were decreased $(\mathrm{p}<0.05)$. On the other hand, error order, no drug dosage, and wrong dosage were increased in the control ward $(\mathrm{p}<0.05)$.

Table 3 shows the frequency and comparison of the types of prescription errors in the wards before and after intervention.

As presented in Table 3, most of the ordering errors occurred in the intervention ward, and illegible error had the highest frequency in the 2 wards before the intervention. Based on Table 3, illegible error was decreased in the intervention ward compared to the control ward.

Table 4 displays the odds ratio of errors in the control ward compared to the intervention ward after CPOE implementation by logistic regression model. In this regard, the variables with significance level less than 0.2 were entered into the model (These variables included illegible order, wrong drug, no drug form, no drug dosage, wrong drug form, wrong dosage, and wrong route.). As illustrated in Table 4, the logistic regression model showed that after CPOE implementation, 2 types of the errors including writing wrong route $(p=0.022)$ and dosage $(p=0.001)$ were increased in the intervention ward compared to the control ward.

\section{Discussion}

The findings of the present study revealed that the CPOE could significantly reduce some of the prescription errors in the intervention ward and in general CPOE and could also reduce ordering errors from $19 \%$ to $3 \%$ in the ICU ward. The use of standard, legible, and clear orders by CPOE was the reason for the errors reduction. The errors are decreased when physicians do not type any word and use standard and default orders. The literature has emphasized the importance of CPOE in prescription errors. In this regard, Villamanan et al. found that MEs decreased from $34 \%$ in the manual system to $2 \%$ after 2 months of CPOE implementation. Moreover, they concluded that CPOE substantially led to MEs and non-drugrelated errors reduction, improved the process of medication use management, and appeared to have a positive economic impact (3). Armada, confirming the results of
Table 1. Frequency, the type and rate of prescribed errors in the intervention ward before and after the intervention in Nemazi hospital

\begin{tabular}{|c|c|c|c|c|c|}
\hline \multirow{2}{*}{$\begin{array}{l}\text { Type of } \\
\text { errors }\end{array}$} & \multicolumn{2}{|c|}{$\begin{array}{l}\text { Before interven- } \\
\text { tion }\end{array}$} & \multicolumn{2}{|c|}{ After intervention } & \multirow{2}{*}{$\mathrm{P}_{-}$value ${ }^{\bullet}$} \\
\hline & $\mathrm{n}(\%)$ & rate & $\mathrm{n}(\%)$ & rate & \\
\hline $\begin{array}{l}\text { Illegible } \\
\text { order }\end{array}$ & $\begin{array}{c}69 \\
(20.0)\end{array}$ & 27.0 & $0(0.0)$ & 0.0 & 0.001 \\
\hline Error order & $7(2.0)$ & 3.0 & $6(6.1)$ & 7.0 & 0.332 \\
\hline Wrong drug & $5(1.4)$ & 2.0 & $0(0.0)$ & 0.0 & 0.727 \\
\hline $\begin{array}{l}\text { No drug } \\
\text { form }\end{array}$ & $86(24.9)$ & 34.2 & $0(0)$ & 0.0 & 0.001 \\
\hline $\begin{array}{l}\text { No drug } \\
\text { dosage }\end{array}$ & $74(21.4)$ & 29.4 & $38(38.7)$ & 41.3 & 0.125 \\
\hline $\begin{array}{l}\text { Wrong drug } \\
\text { form }\end{array}$ & $8(2.3)$ & 3.0 & $8(8.1)$ & 9.0 & 0.001 \\
\hline No route & $16(4.6)$ & 6.3 & $0(0.0)$ & 0.0 & 0.001 \\
\hline $\begin{array}{l}\text { No drug } \\
\text { time }\end{array}$ & $6(1.7)$ & 2.3 & $0(0.0)$ & 0.0 & 0.581 \\
\hline $\begin{array}{l}\text { Wrong } \\
\text { dosage }\end{array}$ & $10(2.8)$ & 4.0 & $31(31.6)$ & 34.0 & 0.001 \\
\hline $\begin{array}{l}\text { Wrong drug } \\
\text { time }\end{array}$ & $29(8.4)$ & 11.5 & $5(5.1)$ & 5.4 & 0.051 \\
\hline Wrong route & $23(6.6)$ & 9.1 & $10(10.2)$ & 10.8 & 0.649 \\
\hline Wrong test & $2(0.5)$ & 0.0 & $0(0.0)$ & 0.0 & 0.625 \\
\hline $\begin{array}{l}\text { Wrong test } \\
\text { time }\end{array}$ & $1(0.2)$ & 0.0 & $0(0.0)$ & 0.0 & 0.318 \\
\hline Wrong diet & $2(0.5)$ & 1.0 & $0(0.0)$ & 0.0 & 0.625 \\
\hline Other errors & $7(2.0)$ & 2.5 & $0(0.0)$ & 0.0 & 0.745 \\
\hline
\end{tabular}

- Test statistic: McNemar

Table 2. Frequency, the type and rate of prescribed errors in the control ward before and after the intervention in Nemazi hospital

\begin{tabular}{|c|c|c|c|c|c|}
\hline \multirow{2}{*}{$\begin{array}{l}\text { Type of } \\
\text { errors }\end{array}$} & \multicolumn{2}{|c|}{$\begin{array}{l}\text { Before interven- } \\
\text { tion }\end{array}$} & \multicolumn{2}{|c|}{ After intervention } & \multirow{2}{*}{$\mathrm{P}_{\text {_value }}{ }^{\bullet}$} \\
\hline & $\mathrm{n}(\%)$ & rate & n (\%) & rate & \\
\hline $\begin{array}{l}\text { Illegible } \\
\text { order }\end{array}$ & $\begin{array}{c}56 \\
(28.0)\end{array}$ & 41.0 & $39(18.1)$ & 21.0 & 0.001 \\
\hline Error order & $6(3.0)$ & 4.0 & $20(9.3)$ & 10.0 & 0.013 \\
\hline $\begin{array}{l}\text { Wrong } \\
\text { drug }\end{array}$ & $7(3.5)$ & 5.0 & $6(2.7)$ & 3.0 & 0.344 \\
\hline $\begin{array}{l}\text { No drug } \\
\text { form }\end{array}$ & $23(11.5)$ & 16.9 & $18(8.3)$ & 9.5 & 0.021 \\
\hline $\begin{array}{l}\text { No drug } \\
\text { dosage }\end{array}$ & $28(14.0)$ & 20.5 & $67(31.1)$ & 35.4 & 0.013 \\
\hline $\begin{array}{l}\text { Wrong } \\
\text { drug form }\end{array}$ & $9(4.5)$ & 6.0 & $7(3.2)$ & 4.0 & 0.227 \\
\hline No route & $10(5.0)$ & 7.3 & $6(2.7)$ & 2.6 & 0.092 \\
\hline $\begin{array}{l}\text { No drug } \\
\text { time }\end{array}$ & $4(2.0)$ & 2.9 & $7(3.2)$ & 2.6 & 0.375 \\
\hline $\begin{array}{l}\text { Wrong } \\
\text { dosage }\end{array}$ & $13(6.5)$ & 10.0 & $24(11.1)$ & 13.0 & 0.001 \\
\hline $\begin{array}{l}\text { Wrong } \\
\text { drug time }\end{array}$ & $23(11.5)$ & 16.9 & $6(2.7)$ & 3.1 & 0.001 \\
\hline $\begin{array}{l}\text { Wrong } \\
\text { route }\end{array}$ & $14(7.0)$ & 10.2 & $7(3.2)$ & 3.7 & 0.004 \\
\hline Wrong test & $2(1.0)$ & 1.0 & $2(0.9)$ & 1.0 & 0.508 \\
\hline $\begin{array}{l}\text { Wrong test } \\
\text { time }\end{array}$ & $1(0.5)$ & 1.0 & $1(0.4)$ & 1.0 & 0.640 \\
\hline Wrong diet & $1(0.5)$ & 1.0 & $2(0.9)$ & 1.0 & 0.549 \\
\hline $\begin{array}{l}\text { Other } \\
\text { errors }\end{array}$ & $3(1.5)$ & 2.2 & $3(1.3)$ & 1.5 & 0.416 \\
\hline
\end{tabular}

this study, indicated that CPOE had an impressive effect on the reduction of prescription errors in ICU wards $(44.8 \%$ to $0.8 \%)(16)$. The results of these 2 studies indicate that CPOE system is successful in preventing medical errors in the hospitals $(4,18)$. Sethuram et al. indicated that CPOE decreased medical errors from 10.4 to 7.3 in a pediatric emergency department. In addition, they empha- 
Table 3. Frequency and comparison of the types of prescription errors in the wards before and after the intervention

\begin{tabular}{|c|c|c|c|c|c|c|}
\hline \multirow[t]{2}{*}{ Type of errors } & \multicolumn{3}{|c|}{ Before intervention } & \multicolumn{3}{|c|}{ After intervention } \\
\hline & $\begin{array}{c}\text { Intervention ward } \\
\mathrm{n}(\%)\end{array}$ & $\begin{array}{c}\text { Control ward } \\
\mathrm{n}(\%)\end{array}$ & P-value $\bullet$ & $\begin{array}{c}\text { Intervention ward } \\
\mathrm{n}(\%)\end{array}$ & $\begin{array}{c}\text { Control ward } \\
n(\%)\end{array}$ & Pvalue ${ }^{\bullet}$ \\
\hline Illegible order & $69(20.0)$ & $56(28.0)$ & 0.006 & $0(0)$ & $39(18.1)$ & 0.001 \\
\hline Error order & $7(2.0)$ & $6(3.0)$ & 0.398 & $6(6.1)$ & $20(9.3)$ & 0.398 \\
\hline Wrong drug & $5(1.4)$ & $7(3.5)$ & 0.087 & $0(0)$ & $6(2.7)$ & 0.084 \\
\hline No drug form & $86(24.9)$ & $23(11.5)$ & 0.003 & $0(0)$ & $18(8.3)$ & 0.002 \\
\hline No drug dosage & $74(21.4)$ & $28(14.0)$ & 0.058 & $38(38.7)$ & $67(31.1)$ & 0.068 \\
\hline Wrong drug form & $8(2.3)$ & $9(4.5)$ & 0.204 & $8(8.1)$ & $7(3.2)$ & 0.081 \\
\hline No route & $16(4.6)$ & $10(5.0)$ & 0.394 & $0(0.0)$ & $6(2.7)$ & 0.290 \\
\hline No drug time & $6(1.7)$ & $4(2.0)$ & 0.744 & $0(0.0)$ & $7(3.2)$ & 0.290 \\
\hline Wrong dosage & $10(2.8)$ & $13(6.5)$ & 0.027 & $31(31.6)$ & $24(11.1)$ & 0.001 \\
\hline Wrong drug time & $29(8.4)$ & $23(11.5)$ & 0.217 & $5(5.1)$ & $6(2.7)$ & 0.359 \\
\hline Wrong route & $23(6.6)$ & $14(7.0)$ & 0.517 & $10(10.2)$ & $7(3.2)$ & 0.018 \\
\hline Wrong test & $2(0.5)$ & $2(1.0)$ & 0.532 & $0(0)$ & $2(0.9)$ & 0.322 \\
\hline Wrong test time & $1(0.2)$ & $1(0.5)$ & 0.659 & $0(0)$ & $1(0.4)$ & 0.485 \\
\hline Wrong diet & $2(0.5)$ & $1(0.5)$ & 0.947 & $0(0)$ & $2(0.9)$ & 0.322 \\
\hline Other errors & $7(2.0)$ & $3(1.5)$ & 0.757 & $0(0)$ & $3(1.3)$ & 0.224 \\
\hline
\end{tabular}

- Test statistic: Chi-squared

Table 4. Odds ratio of errors in the control ward compared to intervention ward after CPOE implementation by Logistic regression model

\begin{tabular}{lccc}
\hline & Control ward versus intervention ward & \\
\hline Error type & $\mathrm{OR}$ & $95 \% \mathrm{CI}$ & $0.152-0.518$ \\
Wrong dosage & 0.281 & $0.113-0.841$ & $\mathrm{P}_{-}$value \\
Wrong route & 0.308 & 0.001 \\
\hline$\bullet$ From logistic regression. The variables entered into the model included; illegible order, wrong drug, no drug form, no drug dosage, wrong drug form, wrong dosage and \\
wrong route.
\end{tabular}

sized that $\mathrm{CPOE}$ integration by electronic medication alert system has more effectiveness (19). Hernandez et al. found the impact of the system on decreasing the prescription errors to be $92 \%$ (2). Because CPOE implementation results in reduction of errors in the ICU, it could be useful for other hospital wards. It is notable that 2 types of errors (wrong route and wrong dosage) were increased with CPOE in the intervention ward, which is important to be taken into account. The dosage of drugs was removed in the system because of the physicians' rapid access to the drug list and they declared that the drug dosage was not necessary in the CPOE, and it was identified as an error in the assessment phase. This weakness of the system, however, is modifiable. In this regard, Sanchez Cuervo et al. indicated that although CPOE could reduce MEs, it may lead to new types of errors, especially in its first implementation. Moreover, they indicated that no new types of MEs were observed once physicians had become accustomed to using the system (20). In addition, Wu et al. stated that several factors had an important role on the efficacy of CPOE such as urgent situations, thus, urgency played a more important role in CPOE numeric typing error-making than typing skills and habits. They recommended that inputting with the numeric keypad had lower error rates in urgent situations (14). Moreover, Mattsson et al. found that the overall risk of a prescription dose error in CPOE system is 1.6 per 100 prescriptions. Also, they stated that the parallel CPOE system did not significantly reduce the overall risk of dose errors, and although it reduced the risk of calculation errors, it introduced other errors (21). Armada et al. found that although errors related to the computerized system are scarce, they may harm patients (16). In addition, Slight et al. found that CPOE systems often failed to detect and prevent important medication errors (22). A study conducted by Hellot-Guersing et al. revealed that CPOE was related to
2.65 errors per 100 orders in hospitals and that configuration issues, misuse, and design problems were the 3 causes identified in this regard (23). In Schift's study, $0.06 \%$ of the medication errors were reported to be CPOE- related. Furthermore, they found that enhanced monitoring, reporting, and testing of CPOE systems were important in improving CPOE safety (24).

In general, due to the effectiveness of CPOE and its user satisfaction (16), it is recommended that hospitals implement the system to reduce medical errors and increase patients' safety and quality of care.

The present study revealed that most of the errors had occurred in the morning shift because in teaching hospitals the important round is done in the morning and most of the orders are noted at this time. Lack of enough time in the rounds and the critical status of the patients are other reasons that cause the physicians to write the order quickly, leading to illegible orders. Another study by the authors revealed that most of the errors occurred in the morning in ICU wards (1).

According to the study results, most of the ordering errors had occurred in the larger and more crowded wards, indicating that a crowded ward is a risk factor for prescription. A study in Iran indicated that medication errors occurred more in large hospitals than in the smaller ones (25). Thus, it is necessary to pay more attention to prescription in large and more crowded wards (1).

\section{Conclusion}

Considering the findings, the use of CPOE significantly reduced the prescription errors. Nonetheless, it is necessary to be more cautious when using the system because it is not an absolutely safe system. Moreover, it is recommended that CPOE be used to improve the quality of delivered services in all wards of the hospitals. Furthermore, it is of high importance to improve the CPOE and elimi- 
nate its weaknesses.

\section{Limitation}

We had no access to some of the medical records in the control group and manual prescription phase because they were used in accounting and legal processes.

\section{Acknowledgements}

The authors would like to thank the Research ViceChancellor of Shiraz University of Medical Sciences for financial support of the research (Contract No. 93-6974).

\section{Funding/support}

The present article was financially supported by Shiraz University of Medical Sciences grants No. 6974.

\section{Conflict of Interests}

The authors declare that they have no competing interests.

\section{References}

1. Khammarnia M, Sharifian R, Keshtkaran A, Zand F, Barati O, Khonia E, et al. Prescribing errors in two ICU wards in a large teaching hospital in Iran. Int J Risk Saf Med. 2015;27(4):169-75.

2. Hernandez F, Majoul E, Montes-Palacios C, Antignac M, Cherrier B, Doursounian L, et al. An Observational Study of the Impact of a Computerized Physician Order Entry System on the Rate of Medication Errors in an Orthopaedic Surgery Unit. PLoS One. 2015;10(7):e0134101.

3. Villamanan E, Armada E, Larrubia Y, Ruano M, Moro M, Herrero A, et al. Impact of Computerized Physician Order Entry on Medication Prescription Errors in Patients Hospitalized in a Chest Diseases Ward. Pharm Anal Acta. 2014;5(5):1-5

4. Charles M, Cannon M, Hall M. Can utilizing a computerized provider order entry (CPOE) system prevent hospital medical errors and adverse drug events?. Perspect Health Inf Manag. 2014;1(11)

5. Franklin BD, Vincent C, Schachter M, Barber N. The incidence of prescribing errors in hospital inpatients. Drug Saf. 2005;28(10):891900 .

6. Goldsmith J, Aikin KJ, Encinosa WE, Nardinelli C. Despite 2007 law requiring FDA hotline to be included in print drug ads, reporting of adverse events by consumers still low. Health Aff. 2012;31(5):1022-9.

7. Colpaert K, Claus B, Somers A, Vandewoude K, Robays H, Decruyenaere J. Impact of computerized physician order entry on medication prescription errors in the intensive care unit: a controlled cross-sectional trial. Crit Care. 2006;10(1):R21.

8. Bloomrosen M, Starren J, Lorenzi NM, Ash JS, Patel VL, Shortliffe EH. Anticipating and addressing the unintended consequences of health IT and policy: a report from the AMIA 2009 Health Policy Meeting. J Am Med Inform Assoc. 2011;18(1):82-90.

9. Khammarnia M, Sharifian R, Zand F, Keshtkaran A, Barati O. Designing Computerized Provider Order Entry Software in Iran: The Nurses' and Physicians' Viewpoints. Comput Inform Nurs. 2016;34(9):413-20.

10. Jones SS, Heaton P, Friedberg MW, Schneider EC. Today's 'meaningful use'standard for medication orders by hospitals may save few lives; later stages may do more. Health Aff. 2011; 30(10):200512 .

11. Rai A, Keil M, Mindel V. How Does Computerized Provider Order Entry Implementation Impact Clinical Care Quality, Cycle Time, and Physician Job Demand Over Time?. Conference on Thirty Sixth International Information Systems. 2015.

12. Manias E, Kinney S, Cranswick N, Williams A, Borrott N. Interventions to reduce medication errors in pediatric intensive care. Ann Pharmacother. 2014;48(10):1313-31.

13. Krive J, Shoolin JS, Zink SD. Effectiveness of Evidence-based Pneumonia CPOE Order Sets Measured by Health Outcomes. Online J Public Health Inform. 2015;7(2).

14. Wu X, Wu C, Zhang K, Wei D. Residents' Numeric Inputting Error in Computerized Physician Order Entry Prescription. Int $\mathrm{J}$ Med Inform. 2016.

15. Nuckols TK, Asch SM, Patel V, Keeler E, Anderson L, Buntin MB, et al. Implementing computerized provider order entry in acute care hospitals in the United States could generate substantial savings to society. Jt Comm J Qual Patient Saf. 2015;41(8):341-50

16. Armada ER, Villamañán E, López-de-Sá E, Rosillo S, Rey-Blas JR, Testillano ML, et al. Computerized physician order entry in the cardiac intensive care unit: effects on prescription errors and workflow conditions. J Crit Care. 2014;29(2):188-93.

17. Nakkas H, Scott PJ, Briggs JS. Health information technology in developing countries: a structured literature review with reference to the case of Libya. Int $\mathrm{J}$ Med, Heal, Biomed and Pharm Eng. 2015;9(1):9-18.

18. Deslich S, Coustasse A. Expanding technology in the ICU: the case for the utilization of telemedicine. Telemed $J$ E Health. 2014;20(5):485-92.

19. Sethuraman U, Kannikeswaran N, Murray KP, Zidan MA, Chamberlain JM. Prescription Errors Before and After Introduction of Electronic Medication Alert System in a Pediatric Emergency Department. Acad Emerg Med. 2015;22(6):714-9.

20. Sanchez Cuervo M, Rojo Sanchis A, Pueyo Lopez C, Gomez de Salazar Lopez de Silanes E, Gramage Caro T, Bermejo Vicedo T. The impact of a computerized physician order entry system on medical errors with antineoplastic drugs 5 years after its implementation. J Clin Pharm Ther. 2015;40(5):550-4.

21. Mattsson T, Holm B, Michelsen H, Knudsen J, Brixen K, Herrstedt J. Non-intercepted dose errors in prescribing anti-neoplastic treatment: a prospective, comparative cohort study. Ann Oncol. 2015;25(5):9816.

22. Slight SP, Eguale T, Amato MG, Seger AC, Whitney DL, Bates DW, et al. The vulnerabilities of computerized physician order entry systems: a qualitative study. J Am Med Inform Assoc. 2016;23(2):311-6

23. Hellot-Guersing M, Jarre C, Molina C, Leromain A, Derharoutunian C, Gadot A, et al. Medication errors related to computerized physician order entry at the hospital: Record and analysis over a period of 4 years. Ann Pharm Fr; 2016;74(1):61-70.

24. Schiff G, Amato M, Eguale T, Boehne J, Wright A, Koppel R, et al. Computerised physician order entry-related medication errors: analysis of reported errors and vulnerability testing of current systems. BMJ Qual Saf. 2015;24(4):264-71.

25. Khammarnia M, Ravangard R, Ghanbari jahromi M, Moradi A. A Study on the Medical Errors in Public Hospitals of Shiraz, 2013. J Hospital. 2014;13(3):17-24. 